AperTO - Archivio Istituzionale Open Access dell'Università di Torino

\title{
Current insights in obstetric antiphospholipid syndrome
}

\section{This is the author's manuscript}

Original Citation:

Availability:

This version is available http://hdl.handle.net/2318/1648001

since 2019-12-13T11:49:40Z

Published version:

DOI:10.1097/GCO.0000000000000406

Terms of use:

Open Access

Anyone can freely access the full text of works made available as "Open Access". Works made available under a Creative Commons license can be used according to the terms and conditions of said license. Use of all other works requires consent of the right holder (author or publisher) if not exempted from copyright protection by the applicable law. 


\section{IIIS AperTO}

UNIVERSITÀ

DEGLI STUDI

DI TORINO

This is the author's final version of the contribution published as:

Current insights in obstetric antiphospholipid syndrome. Schreiber K, Radin M, Sciascia S. Curr Opin Obstet Gynecol. 2017 Dec;29(6):397-403. doi:

10.1097/GCO.0000000000000406. Review. PMID: 28915160

The publisher's version is available at:

https://insights.ovid.com/crossref?an=00001703-201712000-00007

When citing, please refer to the published version.

Link to this full text:

http://hdl.handle.net/2318/1648001

\section{iris-AperTO}




\section{Current insights in obstetricantiphospholipid syndrome}

Karen Schreiber, M.D., MRCP ${ }^{1,2}$

Massimo Radin, M.D. ${ }^{3}$

Savino Sciascia, M.D., PhD ${ }^{3,4}$

${ }^{1}$ Thrombosis \& Thrombophilia, Guy's \& St Thomas'

Hospital, London SE1 7EH, UK

${ }^{2}$ Copenhagen Lupus and Vasculitis Clinic, Center for Rheumatology and Spine Diseases,

Copenhagen University Hospital, Rigshospitalet, Denmark.

${ }^{3}$ Center of Research of Immunopathology and Rare Diseases - Coordinating Center of the Network for Rare Diseases of Piedmont and Aosta Valley, Department of Clinical and Biological Sciences, University of Turin and S. Giovanni Bosco Hospital Turin, Italy

4- Nephrology and Dialysis Unit, Department of Clinical and Biological Sciences, S. Giovanni Bosco Hospital and University of Turin, Turin, Italy

Corresponding author:

Dr Karen Schreiber

Guy's and St Thomas' NHS Foundation Trust, London

Email: Karen.schreiber@gstt.nhs.uk

Financial support: There was no financial support.

Conflict of interests: None of the authors have any conflict of interest. 
Keywords: antiphospholipid syndrome, antiphospholipid antibodies, APS, lupus anticoagulant, anticardiolipin antibodies, anti-beta2glycptrotein1 antibodies, obstetric morbidity

\section{ABSTRACT}

Purpose of the review: Antiphospholipid syndrome (APS) is defined as the association of thrombotic events and/or obstetric morbidity in patients persistently positive for antiphospholipid antibodies (aPL). In this review we will highlight the most important clinical presentations ofAPS with a focus on the obstetric morbidity, the current management strategies and the outlook for the future.

Recent findings: The use of aspirin and heparin has improved the pregnancy outcome in obstetric APS and approximately $70 \%$ of pregnant women with APS have a successful pregnancy outcome. Unfortunately, the current standard of care does not prevent all pregnancy complications as the current treatment fails in $20-30 \%$ of APS pregnancies. This therefore highlights the need for alternative treatments to improve obstetrical outcome.Other treatment options are currently explored and retrospective studies show that pravastatin for example is beneficial in women with aPL related early preeclampsia. Moreover, the immunmodulator hydroxychloroquine (HCQ) may play a beneficial role in the prevention of aPL related pregnancy complications.

Summary: APS is amongst the most frequent acquired risk factors for a treatable cause of recurrent pregnancy loss and increases the risk of conditions associated with ischaemic placental dysfunction, such as fetal growth restriction, pre-eclampsia (PET), premature birth and intrauterine death. Current treatment is mainly based on aspirin and heparin. Studies to inform on alternative treatment options are urgently needed. 


\section{INTRODUCTION(2993 words)}

Antiphospholipid syndrome (APS) is classified as the association of arterial and/or venous thromboses and/or obstetric morbidity in patients who test positive for antiphospholipid antibodies (aPL) on two occasions at least 12 weeks apart. Antibodies currently included in the APS classification criteria are lupus anticoagulant (LA), IgG and/or IgM anti-cardiolipin (aCL) and/or IgG and/or IgM anti-beta2glycoprotein1 antibodies (anti-beta2GP1) ${ }^{1}$.The classification criteria for APS, which often also guide diagnosis, were originally outlined in the Sapporo criteria and were updated in 2006 and are now referred to as the Sydney criteria $^{1,2}$.

Initially, the association of circulating lupus anticoagulant (LA) and anticardiolipin antibodies $(\mathrm{aCL})$, thrombosis, pregnancy loss and thrombocytopenia was described in women suffering from systemic lupus erythematosus (SLE) ${ }^{3}$. This has resulted in that APS in patients with SLE has been referred to as 'secondary', but it is now widely accepted that APS is an autoimmune entity of its own, and that it may well exist in the absence of $\mathrm{SLE}^{4}$.

APS isone of the main acquired prothrombotic conditions that predisposes to venous thromboembolism (also referred to as 'thrombophilia'). Unlike the other thrombophilias, it is unique for APS, that is can also predispose to arterial and microvascular thrombosis.

The other hallmark of this syndrome is pregnancy morbidity, which includes recurrent first trimester pregnancy loss, intrauterine growth restriction (IUGR), pre-eclampsia (PET), premature birth and intrauterine death (IUD) $)^{1,5}$.Data from a retrospective cohort of 500 women with a history of recurrent first trimesterpregnancy loss suggested that $26.4 \%$ are associated with the presence of $\mathrm{aPL}^{6}$. aPL related PET, premature birth or fetal loss are seen in $10-20 \%$ of APS pregnancies ${ }^{7}$. In view of these pregnancy complications, APS has been referred to as the most frequent acquired risk factor for a treatable cause of recurrent pregnancy loss ${ }^{8}$.

The current standard of treatment ofAPS is mainly relying on antithrombotic and antiaggregation treatment ${ }^{9}$.The combination of low dose aspirin (LDA) and heparin (unfractionated heparin (UF) or low molecular weight heparin (LMWH)) has resulted in a live birth rate of $70-80 \%{ }^{10}$. 
Recent data suggest a role for drugs including hydroxychloroquine ${ }^{11,12}$ and pravastatin ${ }^{13}$, but their efficacy and safety in the setting of aPL pregnancies requires confirmation in prospective randomised controlled trials ${ }^{14}$.

The potential beneficial role of pravastatin was highlighted in a retrospective case control study on patients with manifest aPL-related PET and/or IUGR on standard treatment with $\mathrm{LDA}$ and $\mathrm{LMWH}^{13}$. Moreover, the immunmodulator hydroxychloroquine (HCQ) is currently the centre for attention not only in thrombotic but also obstetric APS. Retrospective data suggest, that $\mathrm{HCQ}$ reduces the risk of thrombosis in $\mathrm{APS}^{15}$ and also improves pregnancy outcomes in women with aPL-related pregnancy complications ${ }^{12,16}$. Upcomingrandomised controlled trials will hopefully provide the answer in the near future ${ }^{17}$.

\section{ANTIPHOSPHOLIPID ANTIBODIES}

aPL are a heterogeneous group of antibodies and can be detected in three different ways. Theavailable and required assays detect lupus anticoagulant (LAC), anticardiolipin antibodies $(\mathrm{aCL})$ and anti- $\beta 2$ glycoprotein-I (aß2GPI) and patients may be positive for one, two or three of these tests ${ }^{1}$. The type of $\mathrm{aPL}$, the titre level and the presence of multiple antibodies has been associated with different risk profiles. LAC for example has been described asthe best predictor for pregnancy loss and thrombosis ${ }^{18}$. Some authors suggest that the aPL titre is of clinical interest ${ }^{19}$, especially in aPL-related pregnancy complications where low to medium titre antibodies have been suggested to be of clinical relevance ${ }^{19}$. Regarding the individual specific immunoglobulin isotypes, a positive aCL IgG has been associated to a higher risk of adverse pregnancy outcomes compared to $\operatorname{lgM}$ and $\lg \mathrm{A}$ seems not to be an independent predictor $^{20}$. Galli et al. published a systematic review including 63 studies and concluded that $\mathrm{LAC}$ (and $\mathrm{aCL} \operatorname{lgG}$ ) is the strongest risk factor for thrombosis ${ }^{18}$. The presence of all three antibodies (referred to as 'triple positive' patients) seem to be associated with a high risk for thrombotic APS ${ }^{21}$.

Conversely, there is increasing evidence that patients with low aPL titres can experience poor pregnancy outcomes similarly to high-titre patients ${ }^{19,22,23}$. These observations suggest that, in contrast to thrombotic events, low-titer aPLs can play a significant role in OAPS and that the actual classification criteria do not include all the OAPS cases.

For more specific details on aPL included in the current classification criteria can be read in detail elsewhere ${ }^{24}$. 


\section{PATHOGENESIS}

\section{Thrombosis and fetal loss}

aPL have the unique ability to induce thrombus formation in the arterial and/or venous vasculature and/orthe microcirculation ${ }^{25-27}$. The exact mechanism by which aPL cause prothrombotic changes has been debated, but remains as yet fully explained. aPLhave thepotential to activate several cell types involved in haemostasis including endothelial cells, monocytes and platelets ${ }^{28}$. Other experiments have shown that some aPL are able to inhibit fibrinolysis and the protein C pathway ${ }^{29}$. It is therefore not surprising, that placental thrombosis impairing the maternal-fetal blood exchange has been suggested to play a major role in obstetric APS. Moreover it has been reported that aPL are able to disrupt the anticoagulant annexin A5 shield on trophoblast and endothelial cell monolayers, resulting in fetal loss ${ }^{30,31}$. Ultimately it maybe that multiple mechanisms are responsible for aPL causing thrombosis in one individual.

Placental infarctions were initially thought to be the main cause of fetal loss. However, they werenot the universal histopathological findings in human placental samplesand other mechanisms have therefore been proposed to underlie the pathophysiology of obstetric $\mathrm{APS}^{32}$.De Wolf et al. for example showed that in placental tissues of LAC positive patients, evidence of thrombosis in the placental bed and alsosigns of acute and chronic inflammation ${ }^{33}$. These findings were in line with a study by Stone et al. who found increased infiltration of inflammatory cells, particularly macrophages in placentae of women with aPL 34.

Moreover, it is very likelythat the pathogenesis of aPL-related recurrent pre-embryonic lossdiffers from the pathogenesis of morbidity occurring in late pregnancy ${ }^{35}$.aPL have direct pathogenic effects on placentationand apoptosis of trophoblast cells, which may play an important role, particularly recurrent first trimester losses ${ }^{36}$. This association is supported by murine models, which suggest that the complement system is the key mediator of aPLrelated pregnancy loss and fetal growth restriction. In a pregnant murine model based on BALB/C mice and FcRy mice,mice infused with aPL had increased fetal losses and exhibited fetal growth restriction. Mice with complement deficiency or complement blockage showed protection against aPL induced pregnancy complications, as did treatment with heparins (which have an anti-complement effect) as opposed to fondaparinux with no anticomplement effect ${ }^{37,38}$. Increased complement deposition product were observed in the decidua of pregnant mice infused with aPL, whereas mice depleted of neutrophils or mice 
treated with heparin did not show pregnancy loss or growth restriction and there was a lack of complement deposition in their decidual tissue ${ }^{37}$. The findings from these animal studies were supported by human studies by Shamonki et al., who showed that placentae of women with aPL have increased complement deposition ${ }^{39}$. Thus it is now widely accepted that both thrombosis and inflammation seem to mediate aPL-related ischemic placental pregnancy complications in women with $\mathrm{aPL}^{24}$.

\section{CLINCAL MANIFESTATIONS OF THE ANTIPHOSPHOLIPID SYNDROME}

\section{Thrombotic APS}

As mentioned above, aPL related thrombosis can occur in any vascular bed ${ }^{1}$. The most frequentarterial manifestations are neurological manifestations such as stroke or transient ischaemic attacks (TIA), whereas the most common venous thromboembolic manifestation include deep vein thrombosis (DVT) and pulmonary embolism (PE) ${ }^{7}$.

Other manifestations including retinalartery or vein thrombosis, amaurosis fugax, renal thrombotic microangiopahty,pulmonary hypertension and vascular dementia are seen less frequent in $10 \%$ of patients, whereas adrenal haemorrhage, avascularnecrosis, pathological bone fractures due to bony infarcts or Budd-Chiari Syndromeare seen in $1 \%$ of APS patients ${ }^{40}$. Livedo reticularis, the most common skin manifestation, is sometimes associatedtoocclusive arterial events in the brain and referred to as Sneddon's syndrome ${ }^{7,41}$. The most life-threatening clinical manifestation is rare and referred to as catastrophic APS (CAPS). CAPS is classified by thrombosis in at least three organs often accompanied by small vessel thrombosis developing over a short period and is associated with a mortality of over $50 \%{ }^{4243}$.

Non-thrombotic APS manifestations can include thrombocytopenia, which is usually associated with a risk of thrombosis rather than bleeding complications; cardiac valve abnormalities - minor thickening \&/or incompetence due to valve thrombosis. The valves rarely cause haemodynamic consequences.

\section{Obstetric APS}

\section{Recurrent early miscarriages}

The obstetric manifestations include recurrent first trimester pregnancy loss, and conditions associated with ischaemic placental dysfunction such asintrauterine death, stillbirth, 
PET, premature birth and FGR affecting up to $10-20 \%$ of APS pregnancies ${ }^{140}$. Unfortunately, the definition of miscarriage varies which makes the comparison of reported studies challenging. In Europe, the most widely used definition for early miscarriage is pregnancy loss within the first 12 completed weeks of pregnancy. Ten to $15 \%$ of all clinically recognised pregnancies end inthis way ${ }^{44}$. The most common reasons for early miscarriage and recurrent miscarriages are genetic abnormalities, cervical weakness, anatomic variations, endocrine factors and immune factors, such as thyroid factors, infective agents i.e. TORCH (Toxoplasmosis, Other, Rubella, Cytomegalovirus, Herpes simplex virus) and aPL ${ }^{45}$. In a cohort of 500 women with a history of recurrent miscarriages Rai et al found $9.6 \%$ of women to be persistently positive for $\mathrm{LA}$, whereas aCL $\operatorname{IgG}$ and $\operatorname{IgM}$ were found in $3.3 \%$ and $2.2 \%$, respectively ${ }^{6}$. The prevention of recurrent early miscarriages is the only area in obstetric APS, in which treatment is based on several clinical trials, including randomised controlled trials. This will be discussed in more depth under management.

\section{Late pregnancy loss}

Late pregnancy loss or fetal death is defined as pregnancy loss after 10 weeks of gestation, whereas stillbirth indicates a loss after 20 weeks by some although the definition recommended by WHO for international comparison is a baby born with no signs of life at or after 28 weeks' gestation. The only population based study (the stillbirth collaborative research network) reported the association of aPL ( $\mathrm{aCL}$ and anti- $\beta 2 \mathrm{GPI})$ with a significant increased odds of stillbirth (3-5 fold) in 582 cases of fetal death beyond 20 weeks of gestation. However, the group did not measure LAC, and aCl were not reassessed after 12 weeks interval to confirm persistency of the $\mathrm{aPL}^{46}$.

\section{Placental insufficiency and pre-eclampsia (PET)}

PET and/or placental insufficiency can manifest as fetal growth restriction (FGR) and occurs in about $2-8 \%$ of mainly first pregnancies, whilst severe PET is found in $0.5 \%$ of pregnancies in developed countries. Most prospective observational studies support the association of aPL with PET and placental insufficiency. A recent systematic meta-analysis showed that moderate to high levels $\mathrm{aCL}$ are associated with $\mathrm{PET}^{47}$. Moreover, several prospective and retrospective studies have shown that the persistent presence of high-titre aPL are associated with FGR and preterm deliveries ${ }^{40,48,49}$. Datafrom case control studies have shown that amongst patients with a history of PET or FGR, aPL were found in up to $50 \%$, compared to $7 \%$ or less in healthy pregnant women ${ }^{50}$. There is to date only one randomised controlled 
trial assessing the management and prevention of PET and FGR in women with aPL. The aim of the multicentre study (FRUIT-RCT)was to examine if combined treatment with lowmolecular-weight heparin (LMWH) and aspirin reduces recurrent hypertensive disorders (HD) of pregnancy (HD: pre-eclampsia, eclampsia or HELLP syndrome) in women with aPL with a previous delivery for HD and/or small-for-gestational-age (SGA) birth weight before 34 weeks gestation ${ }^{51}$. Unfortunately, the study was terminated due tovery low event rates and the final analysis on 33 (recruitment target was 85 women to detect a $50 \%$ risk reduction) women did not show any significant difference between aspirin alone or aspirin in combination with $\mathrm{LMWH}^{51}$.

A recent meta-analysis comparing LMWH versus no LMWH for the prevention of recurrent placenta-mediated pregnancy complications in 848 pregnant women with a previous history placental-mediated pregnancy complications showed a relative risk reduction of 0.52 (95\% $\mathrm{Cl}, 0.32$ to 0.86 ) in women treated with $\mathrm{LMWH}^{52}$. The meta-analysis did not confirm any reduction of early pregnancy loss ( $<20$ weeks) in patients with prior placenta-mediated pregnancy complications, whereas a statistically non-significant reduction in late pregnancy loss (>20 weeks) was observed ${ }^{52}$.

Very recently, results from a multicentre randomised controlled trial on $150 \mathrm{mg}$ aspirin once daily versus placebo conducted in 1776 pregnant women at high risk for preterm preeclampsia has shown to reduce the risk of preterm preeclampsia before week 34 of gestation significantly $\left(1,6 \% \text { versus } 4,3 \% \text {, OR } 0.38,95^{\text {th }} \mathrm{Cl} 0.20-0.74 ; p=0.004\right)^{53}$.

\section{MANAGEMENTOF ANTIPHOSPHOLIPID SYNDROME}

\section{Thrombotic APS}

The current mainstay of treatment the thrombotic manifestations of APS is based on anticoagulation, including vitamin $\mathrm{K}$ antagonist (VKA) or heparin and antiplatelet therapy, such as low dose aspirin. Preliminary data supporting the use of direct oral anticoagulant (DOAC) in APS patients with previous venous thromboembolism is available, and other trials are also on-going, as yet the evidence base is incomplete to fully support the use of DOACs in APS. Very rarely immune modulating agents, immunosupression and anti-complement therapy are used in patients who do not respond to antithrombotic medication or in particularly severe conditions such as CAPS.

\section{ObstetricAPS}


Pregnancy in APS are regarded as high risk pregnancies and the main aim of surveillance and treatment in pregnant women with aPL is to optimise maternal and fetal pregnancy outcomes. More specifically, the objective of antenatal care in pregnant patients with APS is close observation for maternal thrombosis, APS nephropathy, hypertension, proteinuria, other features of preeclampsia and to monitor fetal growth.

Current standard of care for patients with obstetric APS includes treatment with low dose aspirin (LDA) (75-100 mg/day) and low molecular heparin (e.g., subcutaneous enoxaparin, dalteparin, nadroparin or subcutaneous tinzaparin) or unfractionated heparin. These recommendations are based on results from three randomised, controlled trials comparing LDA alone or in combination therapy with heparin in women with APS ${ }^{54-56}$. Rai et al. showed a significantly higher rate of live births with LDA plus unfractionated heparin (5000 units BD) versus LDA alone (71\% versus 42\%; odds ratio, 3.37; 95\% confidence interval, 1.40-8.10) ${ }^{54}$. Similarly Kutteh et al., reported a significant improvement in the live birth rate with LDA and heparin versus LDA alone ( $80 \%$ versus $44 \% ; p<0.05)^{56}$. However, no differences in outcome with combination therapy versus LDA was found in two other randomised trials, both using low molecular weight heparin (LMWH), with live birth rates approaching $80 \%$ in both arms. The heterogeneity in the conclusions seems attributable to the relatively poor outcomes in women receiving LDA only in the two former studies ${ }^{55,57}$. Moreover, data from observational studies have reported $79 \%-100 \%$ pregnancy success rates with LDA alone in this subgroup of women ${ }^{58}$. The current recommendation for the treatment of obstetric APS is to start with LDA and to escalate to additional LMWH if LDA alone is associated with pregnancy loss. Data to support this management have recently been published ${ }^{10}$.

\section{PREGNANCY COUNSELLING AND SURVEILLANCE}

Overall there is agreement that pregnant women with obstetric APS require close education and monitoring of maternal and fetal health by a multidisciplinary team consisting of obstetricians, rheumatologists and haematologists with special interest in APS ${ }^{59,60}$. All women should be assessed regarding risk factors for venous thromboembolism and should receive thromboprophylaxis postpartum if indicated according to local guidelines. The Royal College of Gynaecology in the U.K. for example recommends for aPL positive women without clinical manifestations of APS 7 days post partum thromboprphylaxis and for women with APS this is extended to 6 weeks ${ }^{61}$.

All women with APS can potentially give natural birth, unless there are obstetric reasons that suggest otherwise. Moreover, all women should be encouraged to stop smoking and to 
reduce/cease their alcohol intake according to the national pregnancy guidelines. Patients with a recent thrombotic event in the last 3 months, particularly arterial, and/or uncontrolled hypertension should be encouraged to postpone further pregnancies ${ }^{8,24}$. Patients with severe pulmonary hypertension should be advised against pregnancy, because of the high risk of deterioration of such and the risk of maternal death ${ }^{8}$.

Women with previous thrombosis should receive long-term anticoagulation once the risk of post-partum haemorrhage has settled. Both VKA and heparins are compatible with breastfeeding ${ }^{62,63}$. With regards to fetal monitoring during pregnancy, bilateral uterine notching between 23 and 25 weeks' gestation has been shown to be an independent risk factor for the development of early-onset preeclampsia and gestational hypertension. Thus, bilateral uterine artery notching should be considered in the assessment of risk for the development of these pregnancy complications ${ }^{64,65}$.

Thrombotic risk assessment should also be considered in patients with a history of obstetric APS. Among other, Lefèvre et al. showed that patients with obstetric APS have a higher thrombotic risk when compared to healthy women (3.3 vs. $0-0.5 / 100$ patient-years), even if treated with low-dose aspirin (LDA) ${ }^{66}$.

Similarly, in a 10-year observational study of 1592 women with pure obstetric APSand no history of thrombosis, Gris et al. ${ }^{67}$ showed that LA was a risk factor for unprovoked proximal and distal deep and superficial vein thrombosis and similar results have been proved in other studies ${ }^{68}$.

\section{TREATMENT PERSPECTIVES IN OBSTETRIC APS}

The current treatment regimens to prevent obstetric morbidity in APS have improved pregnancy outcome to a live birth rate of over $70 \%$ as mentioned above ${ }^{69}$. As $30 \%$ of women continue to have pregnancy complications, international groups are currently assessing different options in order to improve pregnancy outcomes in women with APS. The additional use of low dosesteroids has been assessed in refractory APS ${ }^{70}$. Intravenous immunoglobulin (IVIG) has been suggested to improve pregnancy complications in obstetric APS, with no significant improvement in pregnancy outcomes ${ }^{71}$.

Interesting data on pravastatin suggest a beneficial role in those women with established aPL-related PET. In their case series 11 patients treated with $20 \mathrm{mg}$ pravastatin in addition to standard treatment, whereas the controls continued LDA and LWMH only. In all patients 
exposed to pravastatin signs of pre-eclampsia, such as blood pressure and proteinuria improved and signs of placental perfusion remained stable without further deterioration compared to the control group ${ }^{13}$.

The role of hydroxychloroquine ( $\mathrm{HCQ}$ ) has also been assessed. The immunmoldulatorHCQ may have beneficial effects not only in the management of thrombotic APS ${ }^{72}$, but also in the prevention of pregnancy complications ${ }^{12,73,74}$. Clinical trials are eagerly awaited ${ }^{75}$. The European randomised controlled multicenter trial 'HYPATIA' will assess the role of HCQ versus placebo in pregnant women with aPL and hopefully provide more robust evidence on the use of HCQ in this setting ${ }^{75}$.

Complement activation, and therefore a potential role for eculizumab, has also been introduced as a potential target for APS therapy. The involvement of complement activation was first investigated in murine models of aPL-related pregnancy morbidities and growing evidences from both in vitro and in vivo studies are emerging ${ }^{37,38}$. Complement can be activated by the binding of $\mathrm{C} 3$ fragment to the Fc receptor of aPL antibodies or by the formation of autoantibodies against C1q, that are frequently detected in patients with $\mathrm{APS}^{76}$. The activation of complement pathway and consequently production of inflammatory molecules like C5a by aPL can directly activate platelets and monocytes, inducing the coagulation cascade, leading to the clinical manifestations of APS.

Although in the current literature, several case reports describe the successful use of eculizumab in severe cases of APS, such as CAPS and cases of APS and thrombotic microangiopathy, the potential role of eculizumab should be further investigated ${ }^{3}$.

\section{SUMMARY}

APS is the most frequent acquired risk factor for a treatable cause of recurrent first trimester pregnancy loss and increases the risk of conditions associated with ischemic placental dysfunction, including stillbirth, intrauterine death, pre-eclamspia, premature birth and fetal 
growth restriction. The current standard of care for obstetric APS is based on aspirin and LMWH. In refractory APS, steroids may play a role to improve pregnancy outcomes. New approaches aiming to improve pregnancy outcomes include the immune-modulator HCQ. Atorvastatin may have some beneficial effect in women with established aPL-related preeclampsia. Randomised controlled trials assessing these new treatment options are eagerly awaited.

\section{REFERENCES}

1. Miyakis $\mathrm{S}$, Lockshin $\mathrm{MD}$, Atsumi $\mathrm{T}$, et al. International consensus statement on an update of the classification criteria for definite antiphospholipid syndrome (APS). J Thromb Haemost 2006; 4(2): 295-306.

2. Wilson WA, Gharavi AE, Koike T, et al. International consensus statement on preliminary classification criteria for definite antiphospholipid syndrome: report of an international workshop. Arthritis Rheum 1999; 42(7): 1309-11.

3. Harris EN. Syndrome of the black swan. Br J Rheumatol 1987; 26(5): 3246.

4. Cervera R, Piette JC, Font J, et al. Antiphospholipid syndrome: clinical and immunologic manifestations and patterns of disease expression in a cohort of 1,000 patients. Arthritis Rheum 2002; 46(4): 1019-27.

5. Levine JS, Branch DW, Rauch J. The antiphospholipid syndrome. $N$ Engl J Med 2002; 346(10): 752-63.

6. Rai RS, Regan L, Clifford K, et al. Antiphospholipid antibodies and beta 2glycoprotein-I in 500 women with recurrent miscarriage: results of a comprehensive screening approach. Hum Reprod 1995; 10(8): 2001-5.

7. Cervera R, Serrano R, Pons-Estel GJ, et al. Morbidity and mortality in the antiphospholipid syndrome during a 10-year period: a multicentre prospective study of 1000 patients. Ann Rheum Dis 2014.

8. Schreiber K, Hunt BJ. Pregnancy and Antiphospholipid Syndrome. Semin Thromb Hemost 2016; 42(7): 780-8.

9. Espinosa G, Cervera R. Current treatment of antiphospholipid syndrome: lights and shadows. Nat Rev Rheumatol 2015; 11(10): 586-96. 
10. Bouvier S, Cochery-Nouvellon E, Lavigne-Lissalde G, et al. Comparative incidence of pregnancy outcomes in treated obstetric antiphospholipid syndrome: the NOH-APS observational study. Blood 2014; 123(3): 404-13.

11. Sciascia S, Hunt BJ, Talavera-Garcia E, Lliso G, Khamashta MA, Cuadrado MJ. The impact of hydroxychloroquine treatment on pregnancy outcome in women with antiphospholipid antibodies. Am J Obstet Gynecol 2016; 214(2): 273 e1-8.**This study suggests a beneficial role of hydroxychloroquine in women with obstetric APS

12. Mekinian A, Lazzaroni MG, Kuzenko A, et al. The efficacy of hydroxychloroquine for obstetrical outcome in anti-phospholipid syndrome: Data from a European multicenter retrospective study. Autoimmun Rev 2015; 14(6): 498-502.

13. Lefkou E, Mamopoulos A, Dagklis T, Vosnakis C, Rousso D, Girardi G. Pravastatin improves pregnancy outcomes in obstetric antiphospholipid syndrome refractory to antithrombotic therapy. J Clin Invest 2016; 126(8): 2933$40{ }^{* *}$ This study suggests a beneficial role of pravastatin in women with aPL related established pre-eclampsia

14. Erkan D, Aguiar CL, Andrade D, et al. 14th International Congress on Antiphospholipid Antibodies: task force report on antiphospholipid syndrome treatment trends. Autoimmun Rev 2014; 13(6): 685-96.

15. Schmidt-Tanguy A, Voswinkel J, Henrion D, et al. Antithrombotic effects of hydroxychloroquine in primary antiphospholipid syndrome patients. J Thromb Haemost 2013; 11(10): 1927-9.

16. Sciascia S HB, Talavera-Garcia E, Lliso G, Khamashta MA and Cuadrado MJ. The impact of hydroxychloroquine treatment on pregnancy outcome in women with antiphospholipid antibodies. accepted in American Journal of Obstetrics \& Gynecology 2015.

17. Schreiber K. SS, Breen K., Jacobsen S., Farquharson R., Middeldorp S., Regan L., Hunt BJ. HYPATIA - A prospective randomised controlled trial of HYdroxychoroquine versus placebo during Pregnancy in women with AnTIphospholipid Antibodies. ISTH 2015.

18. Galli M, Luciani D, Bertolini G, Barbui T. Lupus anticoagulants are stronger risk factors for thrombosis than anticardiolipin antibodies in the antiphospholipid syndrome: a systematic review of the literature. Blood 2003; 101(5): 1827-32.

19. Gardiner C, Hills J, Machin SJ, Cohen H. Diagnosis of antiphospholipid syndrome in routine clinical practice. Lupus 2013; 22(1): 18-25.

20. Opatrny L, David M, Kahn SR, Shrier I, Rey E. Association between antiphospholipid antibodies and recurrent fetal loss in women without autoimmune disease: a metaanalysis. J Rheumatol 2006; 33(11): 2214-21.

21. Pengo $\mathrm{V}$, Ruffatti $\mathrm{A}$, Legnani $\mathrm{C}$, et al. Incidence of a first thromboembolic event in asymptomatic carriers of high-risk antiphospholipid antibody profile: a multicenter prospective study. Blood 2011; 118(17): 4714-8.

22. Boffa MC, Boinot C, De Carolis S, et al. Laboratory criteria of the obstetrical antiphospholipid syndrome. Data from a multicentric prospective European women cohort. Thromb Haemost 2009; 102(1): 25-8.

23. Ofer-Shiber S, Molad Y. Frequency of vascular and pregnancy morbidity in patients with low vs. moderate-to-high titers of antiphospholipid antibodies. Blood Coagul Fibrinolysis 2015; 26(3): 261-6. 
24. Ruiz-Irastorza G, Crowther M, Branch W, Khamashta MA. Antiphospholipid syndrome. Lancet 2010; 376(9751): 1498-509.

25. Pierangeli SS, Liu SW, Anderson G, Barker JH, Harris EN. Thrombogenic properties of murine anti-cardiolipin antibodies induced by beta 2 glycoprotein 1 and human immunoglobulin G antiphospholipid antibodies. Circulation 1996; 94(7): 1746-51.

26. Jankowski M, Vreys I, Wittevrongel C, et al. Thrombogenicity of beta 2glycoprotein I-dependent antiphospholipid antibodies in a photochemically induced thrombosis model in the hamster. Blood 2003; 101(1): 157-62.

27. Ramesh S, Morrell CN, Tarango C, et al. Antiphospholipid antibodies promote leukocyte-endothelial cell adhesion and thrombosis in mice by antagonizing eNOS via beta2GPI and apoER2. J Clin Invest 2011; 121(1): 120-31.

28. Pierangeli SS, Chen PP, Gonzalez EB. Antiphospholipid antibodies and the antiphospholipid syndrome: an update on treatment and pathogenic mechanisms. Curr Opin Hematol 2006; 13(5): 366-75.

29. de Groot PG, Derksen RH. Pathophysiology of antiphospholipid antibodies. Neth J Med 2004; 62(8): 267-72.

30. Meroni PL, Borghi MO, Raschi E, Tedesco F. Pathogenesis of antiphospholipid syndrome: understanding the antibodies. Nat Rev Rheumatol 2011; 7(6): 330-9.

31. Rand JH, Wu XX, Guller S, Scher J, Andree HA, Lockwood CJ. Antiphospholipid immunoglobulin $\mathrm{G}$ antibodies reduce annexin- $\mathrm{V}$ levels on syncytiotrophoblast apical membranes and in culture media of placental villi. Am J Obstet Gynecol 1997; 177(4): 918-23.

32. Out HJ, Kooijman CD, Bruinse HW, Derksen RH. Histopathological findings in placentae from patients with intra-uterine fetal death and anti-phospholipid antibodies. Eur J Obstet Gynecol Reprod Biol 1991; 41(3): 179-86.

33. De Wolf F, Carreras LO, Moerman P, Vermylen J, Van Assche A, Renaer M. Decidual vasculopathy and extensive placental infarction in a patient with repeated thromboembolic accidents, recurrent fetal loss, and a lupus anticoagulant. Am J Obstet Gynecol 1982; 142(7): 829-34.

34. Stone S, Pijnenborg R, Vercruysse L, et al. The placental bed in pregnancies complicated by primary antiphospholipid syndrome. Placenta 2006; 27(4-5): 457-67.

35. Derksen RHWMdGP, G. The obstetric antiphospholipid syndrome. Journal of Reproductive Immunology 2008; 77(1): 41-50.

36. Di Simone N, Meroni PL, de Papa N, et al. Antiphospholipid antibodies affect trophoblast gonadotropin secretion and invasiveness by binding directly and through adhered beta2-glycoprotein I. Arthritis Rheum 2000; 43(1): 140-50.

37. Girardi G, Berman J, Redecha P, et al. Complement C5a receptors and neutrophils mediate fetal injury in the antiphospholipid syndrome. J Clin Invest 2003; 112(11): 1644-54.

38. Girardi G, Redecha P, Salmon JE. Heparin prevents antiphospholipid antibody-induced fetal loss by inhibiting complement activation. Nat Med 2004; 10(11): 1222-6.

39. Shamonki JM, Salmon JE, Hyjek E, Baergen RN. Excessive complement activation is associated with placental injury in patients with antiphospholipid antibodies. Am J Obstet Gynecol 2007; 196(2): 167 e1-5. 
40. Cervera R, Serrano R, Pons-Estel GJ, et al. Morbidity and mortality in the antiphospholipid syndrome during a 10-year period: a multicentre prospective study of 1000 patients. Ann Rheum Dis 2015; 74(6): 1011-8.

41. Sneddon IB. Cerebro-Vascular Lesions and Livedo Reticularis. $\mathrm{Br} J$ Dermatol 1965; 77: 180-5.

42. Cervera R. Update on the diagnosis, treatment, and prognosis of the catastrophic antiphospholipid syndrome. Curr Rheumatol Rep 2010; 12(1): 70-6.

43. Cervera R, Rodriguez-Pinto I, Colafrancesco S, et al. 14th International Congress on Antiphospholipid Antibodies Task Force Report on Catastrophic Antiphospholipid Syndrome. Autoimmun Rev 2014; 13(7): 699-707.

44. Regan L, Braude PR, Trembath PL. Influence of past reproductive performance on risk of spontaneous abortion. BMJ 1989; 299(6698): 541-5.

45. RCOG. The Investigation and Treatment of Couples with Recurrent Firsttrimester and Second-trimester Miscarriage. Green-top Guideline No 172011.

46. Silver RM, Parker CB, Reddy UM, et al. Antiphospholipid antibodies in stillbirth. Obstet Gynecol 2013; 122(3): 641-57.

47. do Prado AD, Piovesan DM, Staub HL, Horta BL. Association of anticardiolipin antibodies with preeclampsia: a systematic review and metaanalysis. Obstet Gynecol 2010; 116(6): 1433-43.

48. Clark EA, Silver RM, Branch DW. Do antiphospholipid antibodies cause preeclampsia and HELLP syndrome? Curr Rheumatol Rep 2007; 9(3): 219-25.

49. Yamada H, Atsumi T, Kobashi G, et al. Antiphospholipid antibodies increase the risk of pregnancy-induced hypertension and adverse pregnancy outcomes. J Reprod Immunol 2009; 79(2): 188-95.

50. Clark EASS, R. M.; Branch, D. W. Do antiphospholipid antibodies cause preeclampsia and HELLP syndrome? Current Rheumatology Reports 2007; 9(3): 219-25.

51. van Hoorn ME, Hague WM, van Pampus MG, Bezemer D, de Vries JI, investigators F. Low-molecular-weight heparin and aspirin in the prevention of recurrent early-onset pre-eclampsia in women with antiphospholipid antibodies: the FRUIT-RCT. Eur J Obstet Gynecol Reprod Biol 2016; 197: 168-73.

52. Rodger MA, Langlois NJ, de Vries JI, et al. Low-molecular-weight heparin for prevention of placenta-mediated pregnancy complications: protocol for a systematic review and individual patient data meta-analysis (AFFIRM). Syst Rev 2014; 3: 69.

53. Rolnik DL, Wright D, Poon LC, et al. Aspirin versus Placebo in Pregnancies at High Risk for Preterm Preeclampsia. N Engl J Med 2017.

54. Rai R, Cohen H, Dave M, Regan L. Randomised controlled trial of aspirin and aspirin plus heparin in pregnant women with recurrent miscarriage associated with phospholipid antibodies (or antiphospholipid antibodies). BMJ 1997; 314(7076): 253-7.

55. Laskin CA, Spitzer KA, Clark CA, et al. Low molecular weight heparin and aspirin for recurrent pregnancy loss: results from the randomized, controlled HepASA Trial. J Rheumatol 2009; 36(2): 279-87.

56. Kutteh WH. Antiphospholipid antibody-associated recurrent pregnancy loss: treatment with heparin and low-dose aspirin is superior to low-dose aspirin alone. Am J Obstet Gynecol 1996; 174(5): 1584-9. 
57. Farquharson RG, Quenby S, Greaves M. Antiphospholipid syndrome in pregnancy: a randomized, controlled trial of treatment. Obstet Gynecol 2002; 100(3): 408-13.

58. Danza A, Ruiz-Irastorza G, Khamashta M. Antiphospohlipid syndrome in obstetrics. Best Pract Res Clin Obstet Gynaecol 2012; 26(1): 65-76.

59. Chighizola CB, Gerosa M, Trespidi L, et al. Update on the current recommendations and outcomes in pregnant women with antiphospholipid syndrome. Expert Rev Clin Immunol 2014; 10(11): 1505-17.

60. Cantwell R, Clutton-Brock T, Cooper G, et al. Saving Mothers' Lives: Reviewing maternal deaths to make motherhood safer: 2006-2008. The Eighth Report of the Confidential Enquiries into Maternal Deaths in the United Kingdom. BJOG 2011; 118 Suppl 1: 1-203.

61. Gynaecologists RCoO. Reducing the Risk of Venous Thromboembolism during Pregnancy and the Puerperium. Green-top Guideline No 37a 2015.

62. Flint J, Panchal S, Hurrell A, et al. BSR and BHPR guideline on prescribing drugs in pregnancy and breastfeeding-Part II: analgesics and other drugs used in rheumatology practice. Rheumatology (Oxford) 2016.

63. Flint J, Panchal S, Hurrell A, et al. BSR and BHPR guideline on prescribing drugs in pregnancy and breastfeeding-Part I: standard and biologic disease modifying anti-rheumatic drugs and corticosteroids. Rheumatology (Oxford) 2016.

64. Espinoza J, Kusanovic JP, Bahado-Singh R, et al. Should bilateral uterine artery notching be used in the risk assessment for preeclampsia, small-forgestational-age, and gestational hypertension? J Ultrasound Med 2010; 29(7): 1103-15.

65. Hunt BJ, Missfelder-Lobos H, Parra-Cordero M, et al. Pregnancy outcome and fibrinolytic, endothelial and coagulation markers in women undergoing uterine artery Doppler screening at 23 weeks. J Thromb Haemost 2009; 7(6): 955-61.

66. Lefevre G, Lambert M, Bacri JL, et al. Thrombotic events during long-term follow-up of obstetric antiphospholipid syndrome patients. Lupus 2011; 20(8): 861-5.

67. Gris JC, Bouvier S, Molinari N, et al. Comparative incidence of a first thrombotic event in purely obstetric antiphospholipid syndrome with pregnancy loss: the NOH-APS observational study. Blood 2012; 119(11): 2624-32.

68. Martinez-Zamora MA, Peralta S, Creus M, et al. Risk of thromboembolic events after recurrent spontaneous abortion in antiphospholipid syndrome: a case-control study. Ann Rheum Dis 2012; 71(1): 61-6.

69. Bramham K, Hunt BJ, Germain S, et al. Pregnancy outcome in different clinical phenotypes of antiphospholipid syndrome. Lupus 2010; 19(1): 58-64.

70. Bramham K, Thomas M, Nelson-Piercy C, Khamashta M, Hunt BJ. Firsttrimester low-dose prednisolone in refractory antiphospholipid antibody-related pregnancy loss. Blood 2011; 117(25): 6948-51.

71. Dendrinos S, Sakkas E, Makrakis E. Low-molecular-weight heparin versus intravenous immunoglobulin for recurrent abortion associated with antiphospholipid antibody syndrome. Int J Gynaecol Obstet 2009; 104(3): 223-5.

72. Tektonidou MG, Laskari K, Panagiotakos DB, Moutsopoulos HM. Risk factors for thrombosis and primary thrombosis prevention in patients with 
systemic lupus erythematosus with or without antiphospholipid antibodies. Arthritis Rheum 2009; 61(1): 29-36.

73. Mekinian A, Costedoat-Chalumeau N, Masseau A, et al. Obstetrical APS: is there a place for hydroxychloroquine to improve the pregnancy outcome? Autoimmun Rev 2015; 14(1): 23-9.

74. Hunt BJ. A novel antiphospholipid antibody agent? Blood 2010; 115(11): 2124-5.

75. Schreiber $\mathrm{K}$, Breen $\mathrm{K}$, Cohen $\mathrm{H}$, et al. HYdroxychloroquine to Improve Pregnancy Outcome in Women with AnTIphospholipid Antibodies (HYPATIA) Protocol: A Multinational Randomized Controlled Trial of Hydroxychloroquine versus Placebo in Addition to Standard Treatment in Pregnant Women with Antiphospholipid Syndrome or Antibodies. Semin Thromb Hemost 2017.

76. Oku K, Nakamura H, Kono M, et al. Complement and thrombosis in the antiphospholipid syndrome. Autoimmun Rev 2016; 15(10): 1001-4. 
